\title{
Influência da adição de alumina na microestrutura da espuma vítrea
}

\section{(Effects of the alumina addition in the microstructure of foam glass)}

\author{
A. Pokorny, J. Vicenzi, C. P. Bergmann \\ Laboratório de Materiais Cerâmicos - LACER, Departamento de Engenharia de Materiais, Universidade \\ Federal do Rio Grande do Sul, Av. Osvaldo Aranha 99/705, Porto Alegre, RS 90035-190
}

\begin{abstract}
Resumo
No presente trabalho estudou-se a influência da adição de alumina nas propriedades da espuma vítrea. A alumina foi empregada com a finalidade de proporcionar uma maior refratariedade para os corpos cerâmicos. Foram investigados corpos cerâmicos à base de vidro sodo-cálcico moído, oriundo de embalagens de vidro transparente, calcário dolomítico e alumina. Os corpos cerâmicos foram formulados com teores de $3 \%$ e $5 \%$ em peso de calcário dolomítico, ambos sem e com $4 \%$ em peso de alumina, conformados por prensagem uniaxial e queimados entre $600{ }^{\circ} \mathrm{C}$ e $1000{ }^{\circ} \mathrm{C}$, com uma taxa de aquecimento de $150 \mathrm{~K} / \mathrm{h}$. A caracterização tecnológica dos corpos cerâmicos envolveu a determinação da expansão volumétrica. A microestrutura foi avaliada por meio de microscopia óptica e eletrônica de varredura. Os resultados experimentais mostraram que a adição de alumina influencia a expansão volumétrica dos corpos cerâmicos, reduzindo a espumação significativamente.

Palavras-chave: espumas vítreas, alumina, porosidade, microestrutura, propriedades.
\end{abstract}

\begin{abstract}
In this work, the influence of the alumina addition on the properties of foam glass was studied. Alumina was introduced to the mixture in order to increase the refractoriness of the final product. Ceramic bodies were composed by ground soda-lime glass from transparent glass bottles, dolomitic lime and alumina. The ceramic bodies were formulated with 3 and $5 \mathrm{wt} \%$ of dolomite lime, both without alumina and with $4 \mathrm{wt} \%$ of this material, uniaxially pressed, and fired in the temperature range from $600{ }^{\circ} \mathrm{C}$ to $1000{ }^{\circ} \mathrm{C}$ at a heating rate of $150 \mathrm{~K} / \mathrm{h}$. The technological characterization of the ceramic bodies involved the determination of the volume expansion. The microstructure was investigated by optical microscopy and scanning electron microscopy. The experimental results show that the addition of alumina influenced the volume expansion of the ceramic bodies, decreasing the foaming.

Keywords: foam glass, alumina, porosity, microstructure, properties.
\end{abstract}

\section{INTRODUÇÃO}

A espuma vítrea é obtida pela adição de um agente espumante ao vidro finamente moído e queimado em temperaturas acima do seu ponto de amolecimento. Esta temperatura é mantida até que o gás liberado pelo agente espumante seja capturado na estrutura do vidro, formando uma grande quantidade de poros $[1,2]$. Sua rota de processamento consiste na espumação, isto é, na formação de espécies gasosas, em uma massa piroplástica de pó de vidro submetida a um fluxo viscoso [3].

A reciclagem da sucata de vidro envolve um grande leque de possibilidades. Além da sua reutilização no próprio processo produtivo, acarretando uma vantajosa diminuição da energia necessária para sua fundição, os resíduos de vidro podem ser reciclados como agregado para cimento Portland e concreto asfáltico, com a economia de agregados naturais comumente utilizados para este fim. Além disso, a sucata de vidro é empregada como agregados para leitos de estradas, materiais abrasivos, blocos de pavimentação, tanques sépticos de sistemas de tratamento de esgoto, filtros, janelas, clarabóias e telhas. Todas estas aplicações utilizam a sucata de vidro moída e/ou em cacos (o tamanho do caco varia conforme a aplicação) adicionada em porcentagens adequadas aos elementos já constituintes [4].

Espumas vítreas representam uma aplicação interessante para resíduos de vidros de um ponto de vista econômico e ambiental [5]. O desenvolvimento da espuma vítrea é particularmente atrativo, pois grandes quantidades de resíduos de vidro podem ser utilizadas como matéria-prima para possível re-uso como produtos comerciais [6].

Pelo tipo de aplicação, a espuma vítrea é uma alternativa para re-utilizar qualquer sucata de vidro, incluindo os contaminados e tóxicos, tais como lâmpadas de mercúrio, escória industrial e cinzas leves, tubos de televisores e de monitores de computadores e vidros laminados para baterias [5]. O processo é baseado no conceito de transformação de pó de vidro de diferentes vidros misturados com um ativador (agente espumante) como carbeto de silício, carbonato de cálcio, óxido de manganês, para a formação da espuma de vidro [5].

Embora a tendência da utilização de resíduos de vidros 
como matérias-primas para a obtenção de outros produtos tenha sido estabelecida nas décadas de 1940 e 1950, um intenso trabalho de pesquisa tem sido realizado para aumentar o uso dos resíduos e ajustar o processamento da espuma vítrea, utilizando-se resíduos específicos e controlando-se a granulometria, a composição química, o tipo de agente espumante, a taxa de aquecimento, entre outros [6].

O uso de resíduos de vidro como matéria-prima para a produção de espumas vítreas requer muitas vezes correções composicionais. Um eventual problema quando se usa vidro derivado dos resíduos é a tendência do vidro cristalizar. Se a cristalização ocorrer durante a espumação, poderão surgir problemas de homogeneidade e de reprodutibilidade [7]. A produção de espumas vítreas a partir de sucata de vidros poderia levar à obtenção de produtos de menor custo por um lado, devido à grande quantidade deste tipo de resíduo que hoje são coletados e, por outro, devido à pouca quantidade de material para obter o mesmo volume que o sólido não expandido. Porém, deve-se observar as dificuldades de processamento relacionadas às mudanças de composição das matérias-primas iniciais, podendo gerar problemas de homogeneidade e reprodutibilidade [6].

O presente trabalho teve por objetivo investigar a influência da adição da alumina, empregada com a finalidade de proporcionar uma maior refratariedade para os corpos cerâmicos, na microestrutura resultante da espuma vítrea para aplicação como isolante térmico e sua expansão volumétrica.

Tabela I - Quantidade de vidro, calcário dolomítico e alumina dos corpos cerâmicos estudados.

[Table I - Amount of glass, dolomite lime and alumina of the studied ceramic bodies.]

\begin{tabular}{cccc}
\hline \multirow{2}{*}{ Nomenclatura } & \multicolumn{3}{c}{ Matérias-primas (\% em peso) } \\
\cline { 2 - 4 } & Vidro & Calcário & Alumina \\
\hline VC3 & 97 & 3 & - \\
VC3A4 & 93 & 3 & 4 \\
VC5 & 95 & 5 & - \\
VC5A4 & 91 & 5 & 4 \\
\hline
\end{tabular}

\section{MATERIAIS E MÉTODOS}

\section{Materiais}

Para o desenvolvimento deste trabalho foram utilizadas como matérias-primas vidro sodo-cálcico, oriundo de embalagens de vidro transparentes, alumina e calcário dolomítico, utilizado como agente espumante. As embalagens de vidro transparentes foram cominuídas, moídas a seco em moinho de bolas e peneiradas até obter tamanho médio de partícula de $80 \mu \mathrm{m}$. O tamanho médio de partícula do calcário dolomítico foi $14 \mu \mathrm{m}$. Os tamanhos médio de partículas foram determinados por espalhamento laser (Cilas 1180).

A alumina utilizada foi APC 2011, ALCOA, com tamanho médio de partículas 2,92 $\mu \mathrm{m}$. Foram desenvolvidas quatro formulações, nas quais foram variadas as proporções de calcário dolomítico e vidro. As formulações estudadas são apresentadas na Tabela I.

A composição química das matérias-primas, determinada por fluorescência de raios X (Shimadzu XRF1800), é apresentada na Tabela II. A composição química do vidro é caracterizada basicamente pela presença predominante de $\mathrm{SiO}_{2}, \mathrm{Na}_{2} \mathrm{O}$ e $\mathrm{CaO}$, típica de um vidro sodo-cálcico, já a do calcário, pela predominância de $\mathrm{CaO}$ e $\mathrm{MgO}$.

As análises mineralógicas do calcário in natura e após calcinação, feitas por difração de raios X em um difratômetro Philips, modelo X'Pert MPD, são mostradas nas Figs. 1a e $1 \mathrm{~b}$, respectivamente. $\mathrm{O}$ resultado da análise mineralógica do calcário in natura acusou a presença das fases dolomita, calcita e antigorita; já o calcário calcinado apresentou as fases magnesita, forsterita, periclásio, óxido de cálcio e silicato de cálcio.

Para avaliar a perda de massa durante o aquecimento, bem como as transformações de origem térmica que o calcário dolomítico pudesse apresentar, procedeu-se à análise de termogravimetria (TG) e termodiferencial (ATD) com uma termobalança Harrop STA-726 até $1000^{\circ} \mathrm{C}$ a uma taxa de aquecimento de $10 \mathrm{~K} / \mathrm{min}$. $\mathrm{O}$ ensaio foi feito em presença de ar sintético, tendo $\mathrm{Al}_{2} \mathrm{O}_{3}$ como material inerte de referência para a definição da linha de base. A Fig. 2 apresenta o resultado para o calcário dolomítico. Pode-se verificar que este apresentou uma perda de massa inicial em torno de $800{ }^{\circ} \mathrm{C}$, pela liberação de $\mathrm{CO}_{2}$. A decomposição do material começa nesta temperatura com um máximo ocorrendo em torno de $900{ }^{\circ} \mathrm{C}$. O primeiro pico endotérmico observado foi a $650{ }^{\circ} \mathrm{C}$, referente à perda de hidroxilas da estrutura da

Tabela II - Composição química do vidro e do calcário dolomítico (\% em peso).

[Table II - Chemical composition of the glass and dolomite lime (wt. \%).]

\begin{tabular}{cccccccccccc}
\hline & $\mathrm{SiO}_{2}$ & $\mathrm{Al}_{2} \mathrm{O}_{3}$ & $\mathrm{Fe}_{2} \mathrm{O}_{3}$ & $\mathrm{MnO}$ & $\mathrm{MgO}$ & $\mathrm{CaO}$ & $\mathrm{Na}_{2} \mathrm{O}$ & $\mathrm{K}_{2} \mathrm{O}$ & $\mathrm{TiO}_{2}$ & $\mathrm{P}_{2} \mathrm{O}_{5}$ & $\mathrm{PF}$ \\
\hline Vidro & 71,25 & 2,12 & 0,15 & 0,03 & 1,62 & 11,58 & 12,38 & 0,75 & 0,07 & 0,05 & ----- \\
Calcário & 15,12 & 1,06 & 0,69 & 0,02 & 20,06 & 27,96 & 0,06 & 0,40 & 0,08 & 0,01 & 33,88 \\
\hline
\end{tabular}



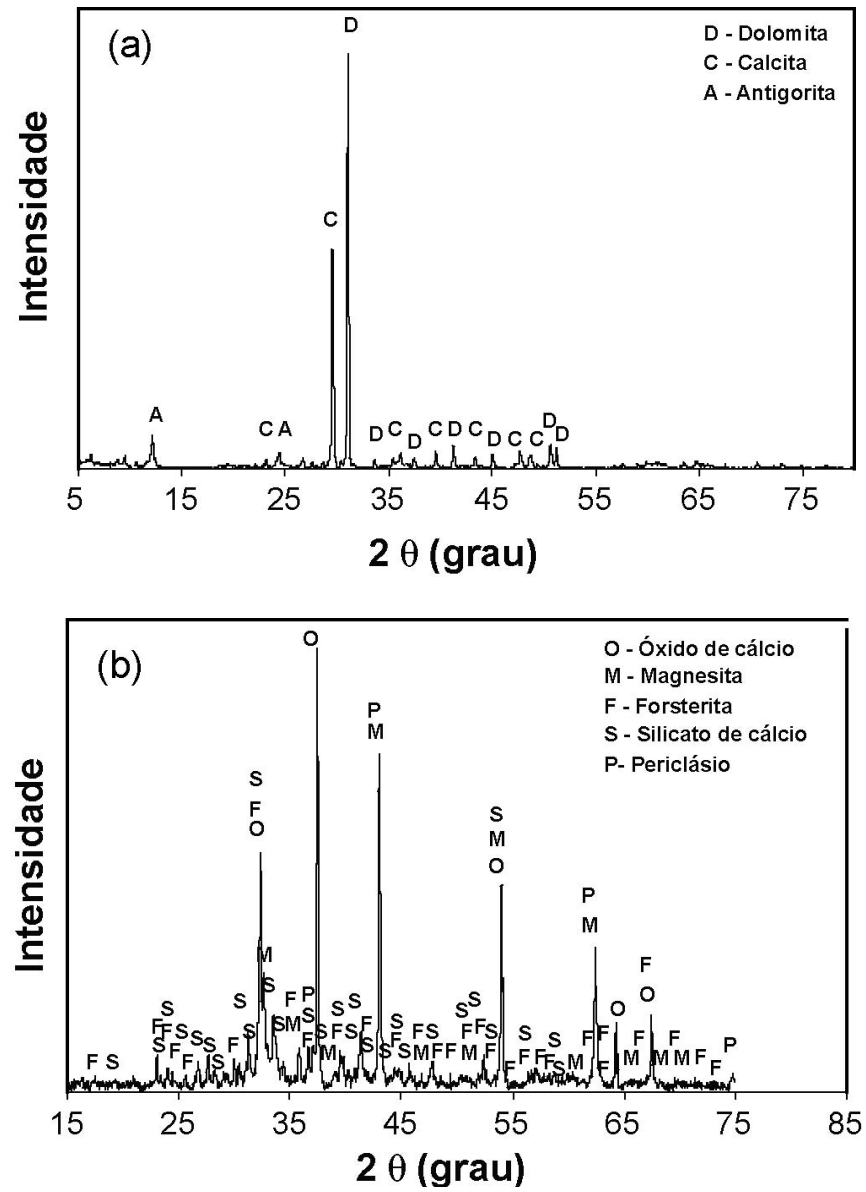

Figura 1: Difratogramas de raios X do calcário: (a) in natura e (b) calcinado a $1000^{\circ} \mathrm{C}$.

[Figure 1: X-ray diffraction patterns of the dolomite lime: (a) in nature and (b) clacined at $1000{ }^{\circ} \mathrm{C}$.]

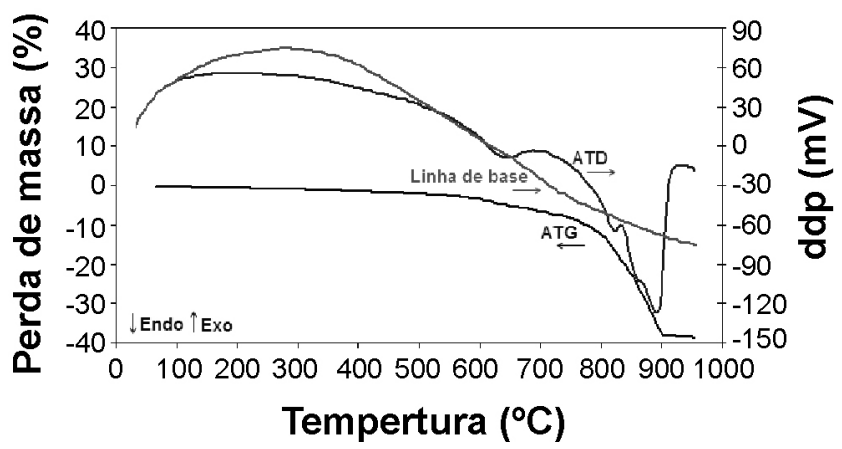

Figura 2: Curvas termogravimétrica e térmica diferencial do calcário dolomítico empregado na formulação das espumas vítreas.

[Figure 2: Thermogravimetric and differential thermal curves of the dolomite lime employed in the foam glass.]

antigorita. Já a 830 e $890{ }^{\circ} \mathrm{C}$ houve a formação do óxido de cálcio e periclásio, respectivamente, ou ainda na forma doloma $(\mathrm{CaO} . \mathrm{MgO})$, confirmando assim que as reações dos gases ocorreram.

\section{Métodos}

Os corpos cerâmicos foram preparados por prensagem uniaxial a $40 \mathrm{MPa}$ com uma matriz de aço ferramenta com as dimensões $20 \times 60 \mathrm{~mm}^{2}$ e queimados em um forno elétrico a $600,700,800,900$ e $1000{ }^{\circ} \mathrm{C}$. A taxa de aquecimento foi $300 \mathrm{~K} / \mathrm{h}$ até $600{ }^{\circ} \mathrm{C}$ e, a partir desta temperatura, $150 \mathrm{~K} / \mathrm{h}$. O tempo de patamar foi $30 \mathrm{~min}$.

Após a queima, determinou-se a expansão volumétrica através da inserção dos corpos cerâmicos em uma proveta, com volume pré-calculado de um material em pó (alumina eletrofundida na granulometria $<180 \mu \mathrm{m}$ ) na qual o acréscimo em altura, devido ao deslocamento do pó, forneceu dados para o cálculo do volume final.

A microestrutura foi avaliada por microscopia óptica e eletrônica de varredura. $\mathrm{Na}$ microscopia óptica, utilizou-se uma lupa Olympus SZ-CTV com câmera digital acoplada, e na microscopia eletrônica de varredura um microscópio Jeol JSM-6060.

\section{RESULTADOS E DISCUSSÃO}

Os gráficos da Fig. 3 apresentam os resultados da expansão volumétrica dos corpos cerâmicos em função da temperatura para as diversas formulações com vidro sodocálcico, calcário dolomítico, com e sem alumina.

A adição de alumina reduziu a espumação do corpo

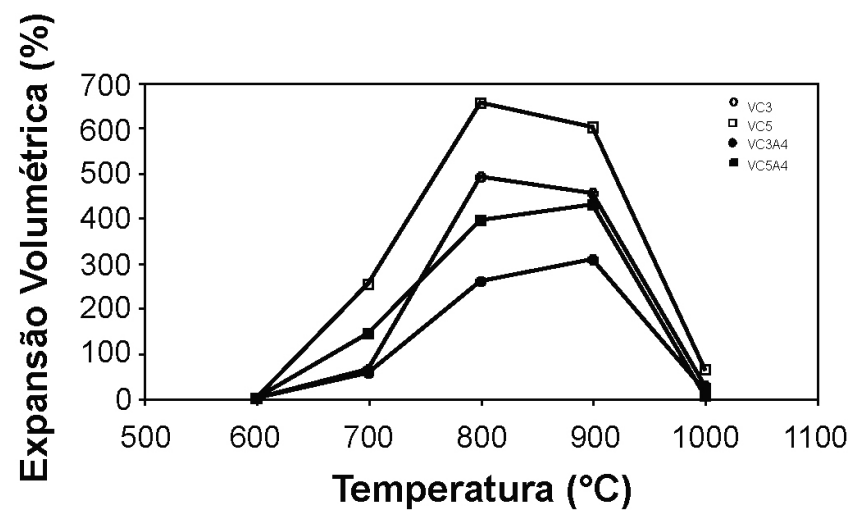

Figura 3: Expansão volumétrica em função da temperatura de queima de espumas vítreas formuladas com 3\% e 5\% de calcário dolomítico, sem e com $4 \%$ de alumina.

[Figure 3: Volumetric expansion as function of firing temperature of foam glasses formulated with 3 and 5 wt.\% dolomite lime, without and with 4 wt.\% alumina.]

cerâmico significativamente. A expansão volumétrica do corpo cerâmico com $3 \%$ de calcário dolomítico e $4 \%$ de alumina, queimado a $800{ }^{\circ} \mathrm{C}$, foi $52,7 \%$ daquela obtida sem a adição de alumina (e $67,8 \%$, quando queimado a $900{ }^{\circ} \mathrm{C}$ ). O mesmo ocorreu para o corpo cerâmico formulado com 5\% de calcário dolomítico com $4 \%$ de alumina em relação ao sem alumina na formulação. A expansão volumétrica do primeiro foi $60,3 \%$ da do segundo, para a temperatura de queima de $800{ }^{\circ} \mathrm{C}\left(71 \%\right.$, quando queimado a $\left.900{ }^{\circ} \mathrm{C}\right)$. $\mathrm{Na}$ análise da 
menor espumação dos corpos cerâmicos com alumina na formulação deve-se considerar que na etapa inicial da queima a fase vítrea mais refratária encontra-se excessivamente viscosa. Assim, boa parte do gás $\mathrm{CO}_{2}$ perde-se, percolando a estrutura de partículas parcialmente vitrificadas. Os corpos cerâmicos obtidos apresentaram a maior expansão quando queimados a $800{ }^{\circ} \mathrm{C}$, para a formulação com $5 \%$ de calcário dolomítico e sem alumina (VC5).

A Fig. 4 apresenta micrografias dos corpos cerâmicos queimados a $900{ }^{\circ} \mathrm{C}$, formulados com $5 \%$ de calcário dolomítico, sem (VC5) e com alumina (VC54A), permitindo uma comparação entre ambos. É possível observar uma parede dos poros mais bem constituída nos corpos cerâmicos formulados com alumina. Sem alumina, os corpos cerâmicos apresentam poros menores e de morfologia mais irregular.
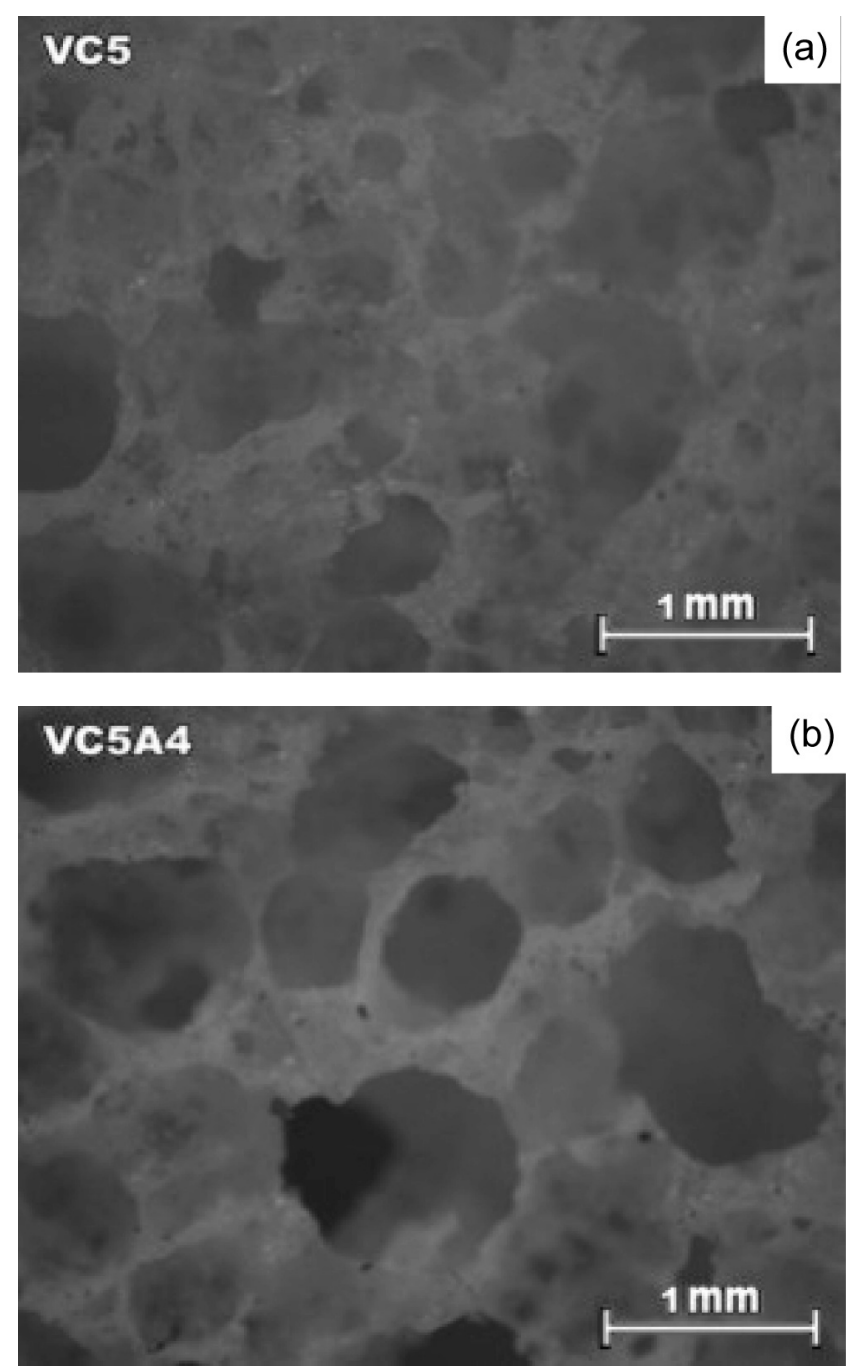

Figura 4: Micrografias obtidas por MEV para comparação entre a porosidade dos corpos cerâmicos formulados com $5 \%$ de calcário dolomítico, sem (VC5) e com (VC5A4) alumina, queimados a $900{ }^{\circ} \mathrm{C}$ (Aumento: 6,7X).

[Figure 4: SEM micrographs for comparsion between porosity of ceramic bodies with $5 \mathrm{wt}$ \% of dolomitic lime, without (VC5) and with (VC5A4) alumina, fired at $900{ }^{\circ} \mathrm{C}$ (Magnification: 6.7X).]

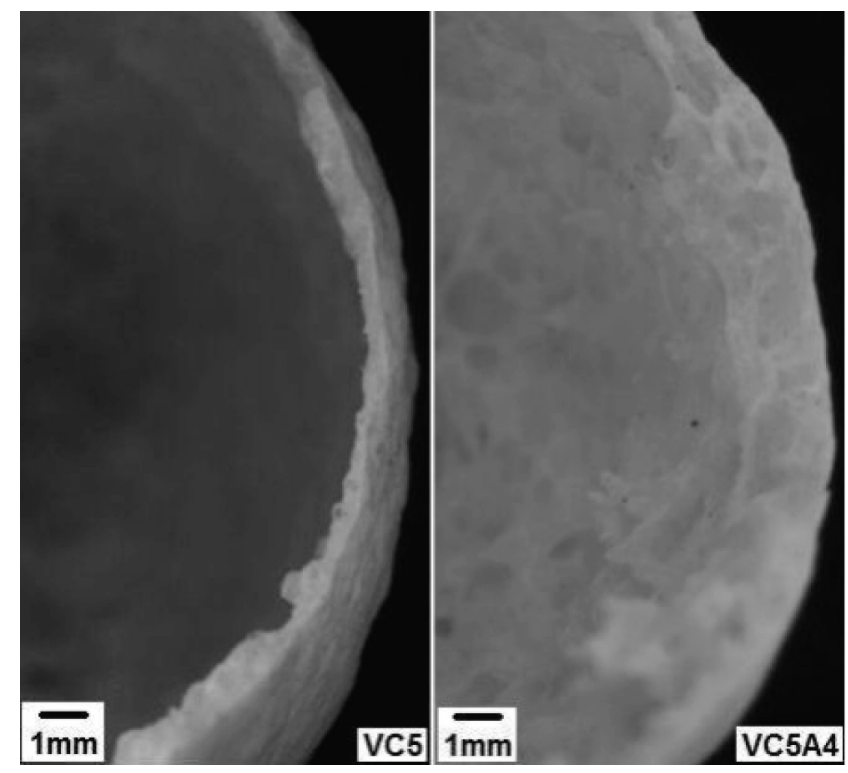

Figura 6: Imagem por lupa da parede dos poros dos corpos cerâmicos formulados com $5 \%$ de calcário dolomítico, sem (VC5) e com (VC5A) alumina, queimados a $900{ }^{\circ} \mathrm{C}$ (aumento: 6,7X).

[Figure 6. Optical images of the wall of the pores of ceramic bodies with 5 wt.\% of dolomitic lime, without (VC5) and with (VC5A4) alumina, fired at $900{ }^{\circ} \mathrm{C}$ (magnification: 6.7X).]
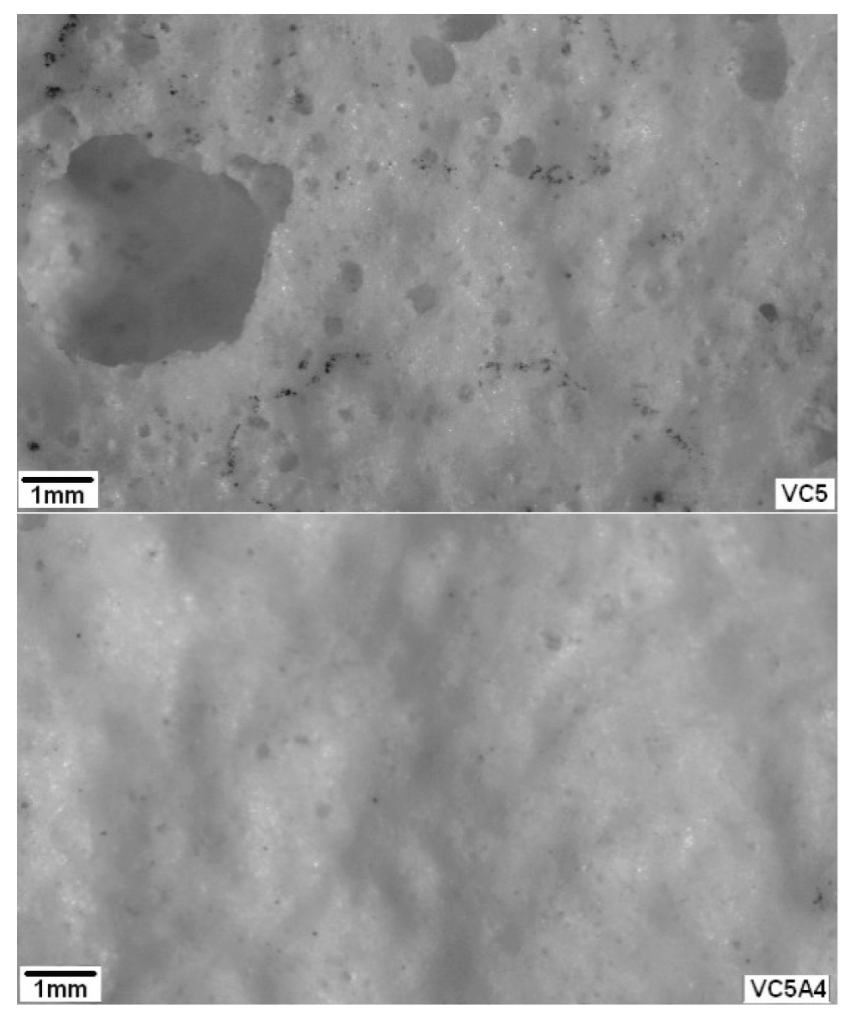

Figura 5: Superfície dos corpos cerâmicos com 5\% de calcário dolomítico, sem (VC5) e com alumina (VC5A4), queimados a temperatura de $900{ }^{\circ} \mathrm{C}$ (aumento: 6,7X).

[Figure 5: Surface of ceramic bodies with 5 wt.\% dolomitic lime, without (VC5) and with (VC5A4) alumina, fired at $900{ }^{\circ} \mathrm{C}$ (magnification: 6.7X).] 
Provavelmente isto se deve ao fato de que a fase vítrea, sendo mais viscosa, apresenta maior resistência à ruptura da parede do poro que está expandindo pela evolução da fase gasosa. Assim, os poros expandem mais, sem perder a fase gasosa pela ruptura da parede do poro. Como resultado, o poro tenderá a um formato mais esférico.

Com o aumento da temperatura, a menor viscosidade da fase vítrea sem alumina e alta produção de fase gasosa no corpo cerâmico, contribuem para que a expansão volumétrica diminua após atingir um máximo, já que levam à formação de orifícios nas paredes dos poros por onde a fase gasosa evolui para fora do corpo cerâmico. Perdendo a fase gasosa, a espuma vítrea perde volume. A Fig. 5 apresenta subsídios para reforçar esta suposição, comparando a superfície dos corpos cerâmicos com $5 \%$ de calcário dolomítico, formulados sem e com alumina. É bastante visível a presença de orifícios na superfície do corpo cerâmico formulados sem alumina, ao contrário do formulado com alumina.

Assim, a viscosidade função da temperatura e da presença de alumina na formulação, da mesma forma que controla o tamanho e esfericidade de poros nas espumas vítreas, é fator determinante para que a espuma vítrea mantenha a expansão volumétrica obtida

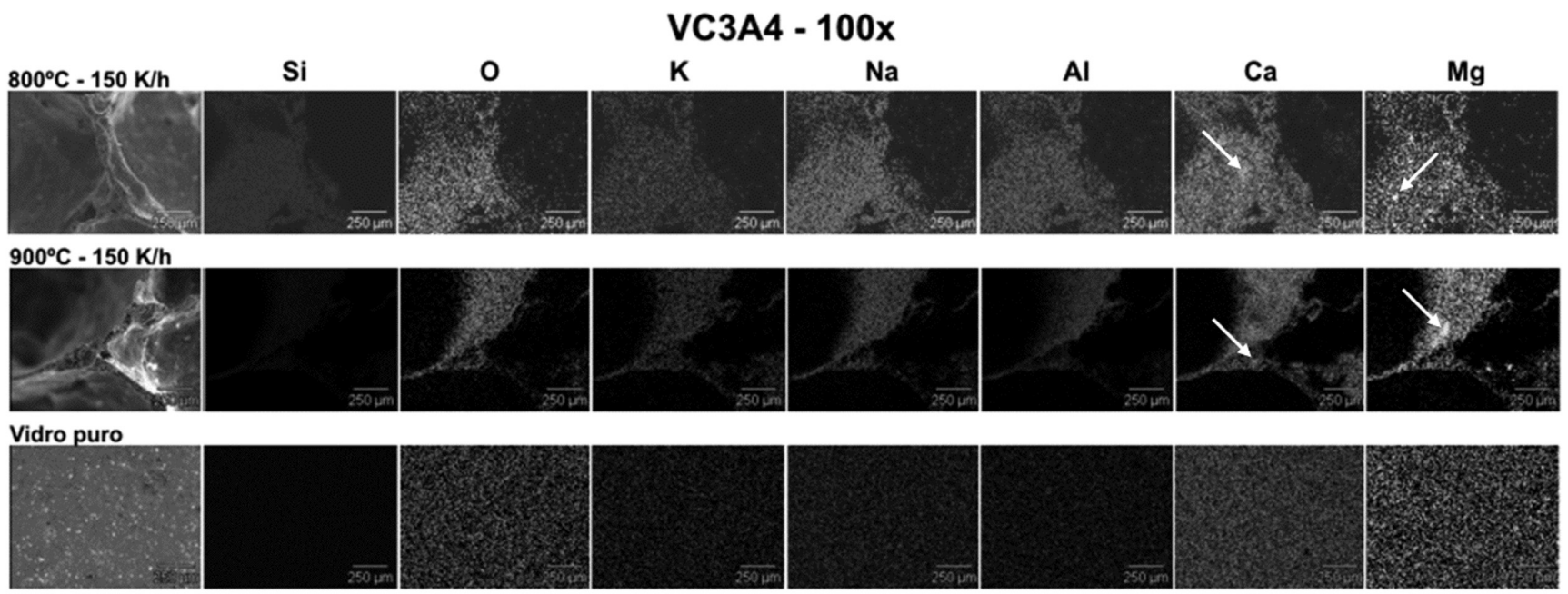

Figura 7: Mapeamento por EDS dos corpos cerâmicos com 3\% em peso de calcário dolomítico e 4\% em peso de alumina (VC3A4) e vidro puro queimados na temperatura de $800{ }^{\circ} \mathrm{C}$ e $900^{\circ} \mathrm{C}$ (aumento: $100 \mathrm{X}$ ).

[Figure 7: EDX elemental mapping of ceramic bodies with 3 wt.\% of dolomitic lime and 4 wt.\% of alumina (VC3A4) and pure glass, fired at $800^{\circ} \mathrm{C}$ and $900^{\circ} \mathrm{C}$ (magnification: 100X).]

VC5A4 - 100x

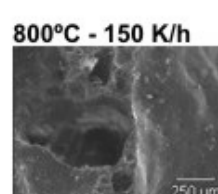

$\mathrm{Si}$

0

K

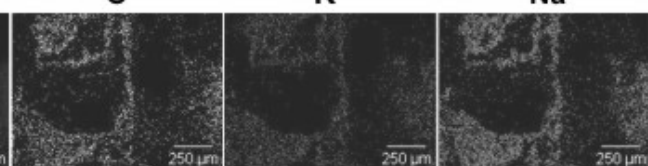

Al

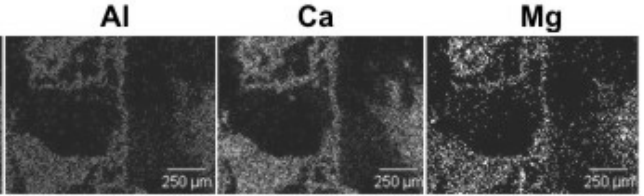

$900^{\circ} \mathrm{C}-150 \mathrm{~K} / \mathrm{h}$
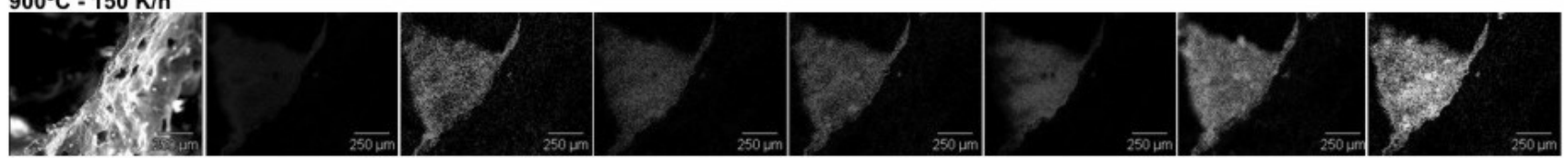

Vidro puro
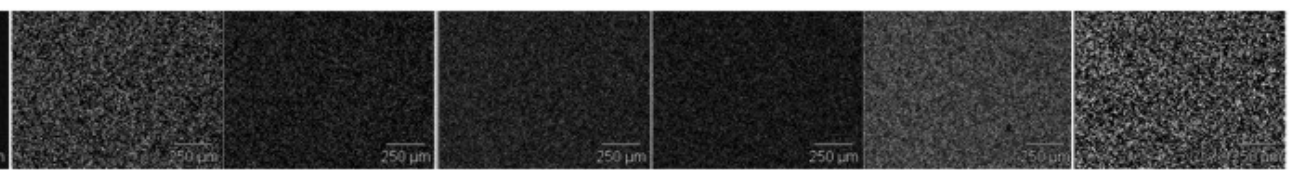

Figura 8: Mapeamento por EDS dos corpos cerâmicos com 5\% em peso de calcário dolomítico e 4\% em peso de alumina (VC5A4) e vidro puro queimados na temperatura de $800{ }^{\circ} \mathrm{C}$ e $900{ }^{\circ} \mathrm{C}$ (aumento: $100 \mathrm{X}$ ).

[Figure 8: EDX elemental mapping of ceramic bodies with 5 wt.\% of dolomitic lime and 4 wt.\% of alumina (VC5A4) and pure glass, fired at $800^{\circ} \mathrm{C}$ and $900^{\circ} \mathrm{C}$ (magnification: 100X).] 
durante a etapa de queima. Nesse processo, a alumina torna a fase vítrea mais viscosa, mais espessa e mais resistente à ruptura, o que a temperaturas mais elevadas retém a expansão volumétrica obtida.

Se forem agora comparadas (Fig. 6) as paredes dos poros dos mesmos corpos cerâmicos da Fig. 5, observa-se que a adição de alumina também leva a uma maior espessura de parede, na qual se pode ainda constatar poros maiores. A região fotografada corresponde a de máxima expansão da bolha na espumação, isto é, à parte de mais alto relevo na superfície da espuma vítrea.

A questão da homogeneização da composição química como fator de influência na espumação dos corpos cerâmicos formulados com alumina foi investigada com o auxílio da técnica de mapeamento de elementos químicos utilizando microssonda EDS. As Figs. 7 e 8 apresentam os resultados obtidos no mapeamento dos corpos cerâmicos com, respectivamente, 3 e $5 \%$ de calcário dolomítico na formulação, ambas com $4 \%$ em peso de alumina. Em todas as amostras optou-se por observar uma região onde fosse possível visualizar as paredes dos poros. Pela análise dos mapeamentos pode-se observar que a maioria dos elementos ficou distribuída homogeneamente tanto para a temperatura de queima de $800{ }^{\circ} \mathrm{C}$ quanto para $900{ }^{\circ} \mathrm{C}$.

A exceção da homogeneidade foi constatada para o magnésio e cálcio, para os quais se observou um acúmulo em alguns pontos localizados nas paredes dos poros maiores (indicados por setas na Fig. 7), mas sem maiores extensões. A alumina não apresentou concentrações que pudessem ser detectadas e que a caracterizariam como não homogeneamente dispersa na fase vítrea. Assim, a queima praticada pode ser considerada suficiente para que ocorressem as reações no sentido da homogeneização da composição da fase vítrea.

\section{CONCLUSÕES}

A presença de alumina na formulação influencia na expansão volumétrica dos corpos cerâmicos, reduzindo a espumação do corpo cerâmico significativamente. A alumina torna a fase vítrea mais viscosa, tendendo a tornar as paredes dos poros mais espessas e mais resistentes à ruptura, o que a temperaturas mais elevadas seria fator de retenção da expansão volumétrica obtida. Já, a ausência de alumina na formulação dos corpos cerâmicos resultou em poros menores de morfologia mais irregular.

O mapeamento dos elementos químicos mostrou que a maioria dos elementos contidos nos corpos cerâmicos ficou distribuída homogeneamente tanto para a temperatura de queima de $800{ }^{\circ} \mathrm{C}$ quanto para $900{ }^{\circ} \mathrm{C}$. Com isso, pode-se concluir que as reações no sentido da homogeneização da composição da fase vítrea ocorreram.

\section{AGRADECIMENTOS}

Ao CNPq e à CAPES pelo apoio no desenvolvimento deste trabalho.

\section{REFERÊNCIAS}

[1] V. Ducman, Sustainable Waste Management and Recycling: Glass waste, Int. Organized by the Concrete and Masonry Research, Kingston University, London (2004) 59-66.

[2]http://www.tno.nl/industrie_en_techniek/productieo ptimalisatie_in/glas_en_keramische_techno/tno

glass_publications/Steiner_ESG_2002.pdf (2002)

[3] E. Bernardo, F. Albertini, Ceram. Int. 32 (2006) 603608.

[4] http://www.reciclagem.pcc.usp.br/artigos.htm. (2006).

[5] R. Aabøe, E. Øiseth, Sustainable Waste Management and Recycling: Glass waste, International Organized by the Concrete and Masonry Research, Kingston University, London (2004) 167-176.

[6] G. Brusatin, E. Bernardo, G. Scarinci, Sustainable Waste Management and Recycling: Glass waste, International Organized by the Concrete and Masonry Research, Kingston University, London (2004) 67-82.

[7] P. Colombo, G. Brusatin, E. Bernardo, G. Scarinci, Curr. Opin. Solid. St. M. 7 (2003) 225-239.

(Rec. 16/07/2007, Ac. 26/10/2007) 